\title{
Structural Elucidation and Antioxidant Activity of a Polysaccharide from Mycelia Fermentation of Hirsutella sinensis Isolated from Ophiocordyceps sinensis
}

\author{
Jin-Hua Liu', Ze-Jian Wang ${ }^{1 *}$, Yu-hua Wang ${ }^{2}$, Ju Chu ${ }^{1 *}$, Ying-Ping, Zhuang ${ }^{1}$ and Si-Liang Zhang ${ }^{1}$ \\ ${ }^{1}$ State Key Laboratory ofBioreactor Engineering, East China University of Science and Technology, Shanghai 200237, China \\ ${ }^{2}$ Zhu Feng Ophiocordyceps Pharmacy Corporation, Ltd. P R Qinghai, China
}

\begin{abstract}
The structure and antioxidant activity of a polysaccharide from mycelia fermentation of Hirsutella sinensis were analyzed. The natural active component water-soluble polysaccharides was isolated from mycelia, and three polysaccharide fractions HSP-1, HSP-2, and HSP-3 were purified with chromatography and the structures were identified. The structural characteristics determination with a combination of chemical and instrumental analysis methods showed that the mainly component HSP-1 was about $1.7 \times 10^{4} \mathrm{Da}$, and composed of glucose, mannose and galactose at a molar ratio of 4.5:1.0:1.4. Further researches revealed that HSP-1 was a branched polysaccharide possessing a backbone of $(1 \rightarrow 4)$ - $\alpha$-D-glucose residues $(\sim 70 \%),(1 \rightarrow 4)-\alpha$-D-mannose residues $(\sim 15 \%)$ and $(1 \rightarrow 4)$ - $\alpha$-D-galactose residues $(\sim 15 \%)$. The branches were at the $(1,2,4,6 \rightarrow)$ - $\alpha$-D-glucose residues $(\sim 8 \%)$ of the backbone, mainly composed of $(1 \rightarrow 4)-\alpha$-D-glucose residues, $(1 \rightarrow 4)-\alpha$-D-galcatose residues, $(1 \rightarrow 4)-\alpha$-D-mannose residues, and terminated with $\alpha$-D-galactose residues. The in vitro antioxidant assay proved HSP-1 possessed the hydroxyl radical-scavenging activity with an $I C_{50}$ value of $0.834 \mathrm{mg} / \mathrm{mL}$.
\end{abstract}

Keywords: Ophiocordyceps sinensis; Hirsutella sinensis; Mycelia fermentation; Polysaccharide structure; Antioxidant activity

Nomenclature: HSP: Hirsutella sinensis polysaccharide; $I C_{50}$ : The polysaccharide concentration for hemi-inhibitable hydroxyl radical; IPS: Intracellular polysaccharides

\section{Introduction}

In recent years, many polysaccharides and polysaccharide-protein complexes isolated from fungi have been used as a source of therapeutic agents $[1,2]$. Many studies showed that fungi polysaccharide have series of pharmacological action, including anti-oxidation, hypoglycemic, boost immunity, anti-fatigue and anti-cancer [3-7]. Therefore, it is significant to discover and extract the valuable polysaccharides from fungi as safe compounds for functional foods or medicine.

O. sinensis, called Cordyceps or Dong Chong Xia Cao in China, is one of the most valuable traditional Chinese medicinal fungi. It is generally used to nourish the kidney, moisten the lung, fight fatigue and enhance immunity [8]. Furthermore, the wild $O$. sinensis is exiguity and expensive in the market, so the mycelia fermentation has become to an economical method to meet large requirement of the market [5]. Several Intracellular Polysaccharides (IPS) have been purified from the mycelia of $O$. sinensis, and the molecular structures have been elucidated [9-11]. In this study, the mycelia we used are called Hirsutella sinensis, which is a novel fungus isolated from the fruiting body of the wild $O$. sinensison the Tibetan Plateau. It has been identified as an anamorphic fungus by the Chinese Academy of Sciences. Numerous liquid fermentations have been conducted to optimize the production of mycelia biomass. However, the IPS purified from $H$. sinensis has not been reported yet.

Since the structure of IPS is closely related with its functions, it would be of interest for an in-depth research. The aim of this study is to characterize the molecular structure and antioxidant activity of the polysaccharide, HSP-1, which was isolated and purified from the crude IPS produced by the H.sinensis liquid fermentation.

\section{Materials and Methods}

\section{Fungus and mycelia fermentation}

The strain used in this research was Hirsutella sinensis, which was identified as the anamorph of Ophiocordyceps sinensis [12,13]. $0.8 \mathrm{~L}$ culture was pre-cultivated in a $1 \mathrm{~L}$ flask for 10 days at $16^{\circ} \mathrm{C}, 180 \mathrm{rpm}$ and natural $\mathrm{pH}$. The medium consists of, in $(\mathrm{g} / \mathrm{L})$ : glucose $(30.0)$, yeast extract (22.0), $\mathrm{KH}_{2} \mathrm{PO}_{4}(0.1), \mathrm{MgSO}_{4} .7 \mathrm{H}_{2} \mathrm{O}(0.05)$. Then it was transferred to a $50 \mathrm{~L}$ fermentation tank by $10 \%(\mathrm{v} / \mathrm{v})$ inoculums size in a liquid medium, which containing, in $(\mathrm{g} / \mathrm{L})$ : glucose $(40.0)$, yeast extract (33.0), $\mathrm{KH}_{2} \mathrm{PO}_{4}(0.1), \mathrm{MgSO}_{4} .7 \mathrm{H}_{2} \mathrm{O}(0.05)$. The total volume of the fermentation medium was $30 \mathrm{~L}$, cultivated for 10 days at $16^{\circ} \mathrm{C}$, 200rpm. During the fermentation process, the pHwas natural. After the fermentation finished, the mycelium was collected and dried at $60^{\circ} \mathrm{C}$ for $24 \mathrm{~h}$.

\section{Isolation and purification of polysaccharide}

The dried $H$. sinensis mycelium was extracted by deionized water at $100^{\circ} \mathrm{C}$ for $90 \mathrm{~min}$, and the ratio of solid to liquid was $1: 10(\mathrm{w} / \mathrm{v})$, which was repeated three times. The supernatant was collected

*Corresponding authors: Ze-Jian Wang, State Key Laboratory of Bioreactor Engineering, East China University of Science and Technology P.O. Box 329, 130 Meilong Road, Shanghai 200237 People's Republic of China, Fax: +86-21-642-522-52; E-mail: wangzejian@ecust.edu.cn

Ju Chu, State Key Laboratory of Bioreactor Engineering, East China University of Science and Technology P.O. Box 329, 130 Meilong Road, Shanghai 200237 People's Republic of China, Fax: +86-21-642-537-02;E-mail: juchu@ecust.edu.cn

Received September 10, 2014; Accepted November 04, 2014; Published November 07, 2014

Citation: Liu JH, Wang ZJ, Wang Y, Chu J, Zhuang YP, et al. (2014) Structural Elucidation and Antioxidant Activity of a Polysaccharide from Mycelia Fermentation of Hirsutella sinensis Isolated from Ophiocordyceps sinensis. J Bioprocess Biotech 4: 183 doi: 10.4172/2155-9821.1000183

Copyright: (c) $2014 \mathrm{Liu} \mathrm{JH}$, et al. This is an open-access article distributed under the terms of the Creative Commons Attribution License, which permits unrestricted use, distribution, and reproduction in any medium, provided the original author and source are credited. 
Citation: Liu JH, Wang ZJ, Wang Y, Chu J, Zhuang YP, et al. (2014) Structural Elucidation and Antioxidant Activity of a Polysaccharide from Mycelia Fermentation of Hirsutella sinensis Isolated from Ophiocordyceps sinensis. J Bioprocess Biotech 4: 183 doi: 10.4172/21559821.1000183

Page 2 of 6

after and concentrated under reduced pressure. It was mixed with 3 volume of ethanol and precipitated for $24 \mathrm{~h}$ at $4^{\circ} \mathrm{C}$ to obtain the crude polysaccharide. The protein was removed by Sevag method [14], and dialyzed against running water and deionized water for $48 \mathrm{~h}$. After the non-dialyzable phase was precipitated with 3 volume of ethanol, the precipitation was collected by centrifugation. The precipitation was washed with absolute ethyl alcohol, acetone and diethyl ether, and finally was dried under vacuum.

The obtained crude polysaccharide was purified by DEAE-cellulose column eluted with gradient $\mathrm{NaCl}$ aqueous solution $(0-1 \mathrm{M})$. The fractions were collected and detected by phenol-sulfuric acid [15]. The resulting fractions were further purified by Sephadex G-100 column eluted with deionized water. Three polysaccharide fractions were detected after purification process, which were termed HSP-1, HSP2 , and HSP-3 respectively. The main fraction HSP-1 was used for the further structure elucidation and antioxidant activity assay.

\section{Homogeneity and molecular weight measurement of HSP-1}

The homogeneity of HSP-1 was measured by Sephacryl S-300 HR column chromatography and Ultraviolet (UV) spectroscopy scanning. Gel chromatographic method $[9,16]$ was used to measure the molecular weight of HSP-1. The blue dextran 2000 and different weight-average molecular weights standard dextrans T-500, T-70, T-40 and T-10 were passed through the Sephacryl S-300 HR column, eluted with deionized water at a flow rate of $0.2 \mathrm{~mL} / \mathrm{min}$. The standard curve was established using the elution volumes plotted against the negative logarithms of their known molecular weights. HSP-1 $(5 \mathrm{mg})$ dissolved in deionized water $(0.5 \mathrm{~mL})$ passed through the column, so the molecular weight of HSP-1 was obtained by plotting the elution volume with the standard curve.

\section{Analysis of monosaccharide composition}

Dried HSP-1 (5 mg) was hydrolyzed with $2 \mathrm{~mL}$ trifluoroacetic acid (TFA) $(2 \mathrm{M})$ at $100^{\circ} \mathrm{C}$ for $8 \mathrm{~h}$. After the hydrolysis finished, excess acid evaporated under reduced pressure and then washed three times with absolute ethyl alcohol. The hydrolysate with $20 \mathrm{mg}$ methoxylamine hydrochloride was dissolved in $1 \mathrm{~mL}$ pyridine at $70^{\circ} \mathrm{C}$ for $2 \mathrm{~h}$, then $150 \mu \mathrm{L}$ of the sample was mixed with $100 \mu \mathrm{L}$ of bis(trimethylsilyl) trifluoroacetamide (trimethylchlorosilane $1 \%$ ) derivatized at $70^{\circ} \mathrm{C}$ for 1 h. The silylation derivatized sample was ready for Gas ChromatographMass Spectrometer (GC-MS) analysis. GC-MS analysis was conducted with an Agilent Technologies 7890A/5975C instrument, using a HP$5 \mathrm{MS}$ capillary column $(30 \mathrm{~m} \times 0.25 \mathrm{~mm} \times 0.25 \mathrm{~nm})$. The initial column temperature was kept at $70^{\circ} \mathrm{C}$ for $4 \mathrm{~min}$, first increased to $200^{\circ} \mathrm{C}$ at $3^{\circ} \mathrm{C} /$ min, kept for $0 \mathrm{~min}$, and then increased to $300^{\circ} \mathrm{C}$ at $10^{\circ} \mathrm{C} / \mathrm{min}$, kept for 5 $\mathrm{min}$. The ionization potential was $70 \mathrm{eV}$ and the temperature of the ion source was $280^{\circ} \mathrm{C}$. Similarly, the standard monosaccharides D-glucose, $\mathrm{D}$-mannose, $\mathrm{D}$-galactose, $\mathrm{D}$-arabinose $\mathrm{D}$-xylose and $\mathrm{D}$-inositol were derivatized.

\section{Periodate oxidation-Smith degradation}

The HSP-1 $(20 \mathrm{mg})$ was oxidized with $15 \mathrm{mM} \mathrm{NaIO}_{4}(20 \mathrm{~mL})$ and kept in the dark at $4^{\circ} \mathrm{C} .100 \mu \mathrm{L}$ aliquots were withdrawn for every $12 \mathrm{~h}$, the aliquots were diluted to $25 \mathrm{~mL}$ and tested using a spectrophometer at $223 \mathrm{~nm}$ [17]. The oxidation was stopped by adding $1 \mathrm{~mL}$ glycol until the absorbance did not change any more. The production of $\mathrm{HCOOH}$ was measured by titration with $0.005 \mathrm{M} \mathrm{NaOH}$ and the consumption of $\mathrm{NaIO}_{4}$ was determined by spectrophotometric methods [18]. The solution was dialyzed against running water and deionized water each for $24 \mathrm{~h}$, reduced by $\mathrm{NaBH}_{4}(70 \mathrm{mg}$ ) overnight, neutralized with $50 \%$ acetic acid, dialyzed against running water and deionized water each for $24 \mathrm{~h}$, and vacuum dried. The product was hydrolyzed with $2 \mathrm{M}$ trifluoroacetic acid (TFA) at $100^{\circ} \mathrm{C}$ for $8 \mathrm{~h}$ in a sealed tube and analyzed by GC-MS with the same method as mentioned above for the analysis of monosaccharide composition.

\section{Methylation analysis}

The HSP-1 $(20 \mathrm{mg})$ was methylated by the method of Needs and Selvendran [19]. The methylated HSP-1 was depolymerized with $90 \%$ $\mathrm{HCOOH}$ for $6 \mathrm{~h}$ at $100^{\circ} \mathrm{C}$. The residues were hydrolyzed with $2 \mathrm{M}$ TFA $(2 \mathrm{~mL})$ for $8 \mathrm{~h}$ after removal of the $\mathrm{HCOOH}$. The resulting products were silylation derivatized and analyzed by GC-MS as the method mentioned for the analysis of monosaccharide composition. The methylated sugar linkages were identified on the basis of the retention time and fragmentation patterns $[19,20]$.

\section{Partial hydrolysis of HSP-1}

The HSP-1 $(100 \mathrm{mg})$ was hydrolyzed by $0.05 \mathrm{M}$ TFA $(4 \mathrm{~mL})$ at $100^{\circ} \mathrm{C}$ for $12 \mathrm{~h}$, After dilution the products with deionized water and dialyzed against deionized water for $24 \mathrm{~h}$ in a dialysis bag (cut off 3, 500 $\mathrm{Da})$, the solution in the bag was diluted with ethanol. The fraction out of the bag and the precipitate and supernatant in the bag were collected, driedand hydrolyzed. GC-MS analysis was carried out to understand the monosaccharide composition.

\section{IR analysis}

1mg HSP-1 was ground and mixed with $\mathrm{KBr}$ before being flaked. TheInfra-Red (IR) spectrums werescanned in the range of 400-4000 $\mathrm{cm}^{-1}$ on a Nicolet 6700 Fourier transformed IR spectrophotometer.

\section{NMR spectroscopy}

20 mg HSP-1 was dried under vacuum over $\mathrm{P}_{2} \mathrm{O}_{5}$ for several days and then put it into a 5-mm Nuclear Magnetic Resonance (NMR) tube with $1 \mathrm{~mL}$ of $\mathrm{D}_{2} \mathrm{O}$. NMR $\left({ }^{1} \mathrm{H},{ }^{13} \mathrm{C}\right)$ spectra were accomplished with a Bruker 400 spectrometer.

\section{Hydroxyl radical-scavenging activity}

Hydroxyl radical-scavenging assay was carried out by Fenton's reaction method described by $\mathrm{He}$ et al. [21] with a slight modification. Briefly, the reaction mixture included $1.0 \mathrm{~mL}$ of brilliant green $(0.435$ $\mathrm{mM}), 2.0 \mathrm{~mL}$ of $\mathrm{FeSO}_{4}(0.5 \mathrm{mM}), 1.5 \mathrm{~mL}$ of $\mathrm{H}_{2} \mathrm{O}_{2}(3.0 \%), 0.5 \mathrm{~mL}$ samples of different concentrations and was made up to $5.0 \mathrm{~mL}$ with deionized water. The absorbance of the reaction mixture was measured at $624 \mathrm{~nm}$ after incubating at room temperature for $20 \mathrm{~min}$.

The hydroxyl radicals can eliminate the brilliant green, so the scavenging ability for hydroxyl radical can be characterized by the absorbance variation of the reaction mixture. The hydroxyl radicalscavenging activity can be expressed as:

$$
\text { Scavenging rate }(\%)=\left(A_{\mathrm{O}}-A_{\mathrm{S}}\right) /\left(A-A_{\mathrm{O}}\right) \times 100 \%(1)
$$

Where, $A_{\mathrm{S}}$ is the absorbance of the mixture with the sample, $A_{\mathrm{O}}$ is the absorbance of the control without the sample and $A$ is the absorbance in the absence of the sample and Fenton reaction system. Vc was used as a control.

\section{Statistical analysis}

The data were expressed as means \pm SD. A statistical analysis of 
Citation: Liu JH, Wang ZJ, Wang Y, Chu J, Zhuang YP, et al. (2014) Structural Elucidation and Antioxidant Activity of a Polysaccharide from Mycelia Fermentation of Hirsutella sinensis Isolated from Ophiocordyceps sinensis. J Bioprocess Biotech 4: 183 doi: $10.4172 / 2155-$ 9821.1000183

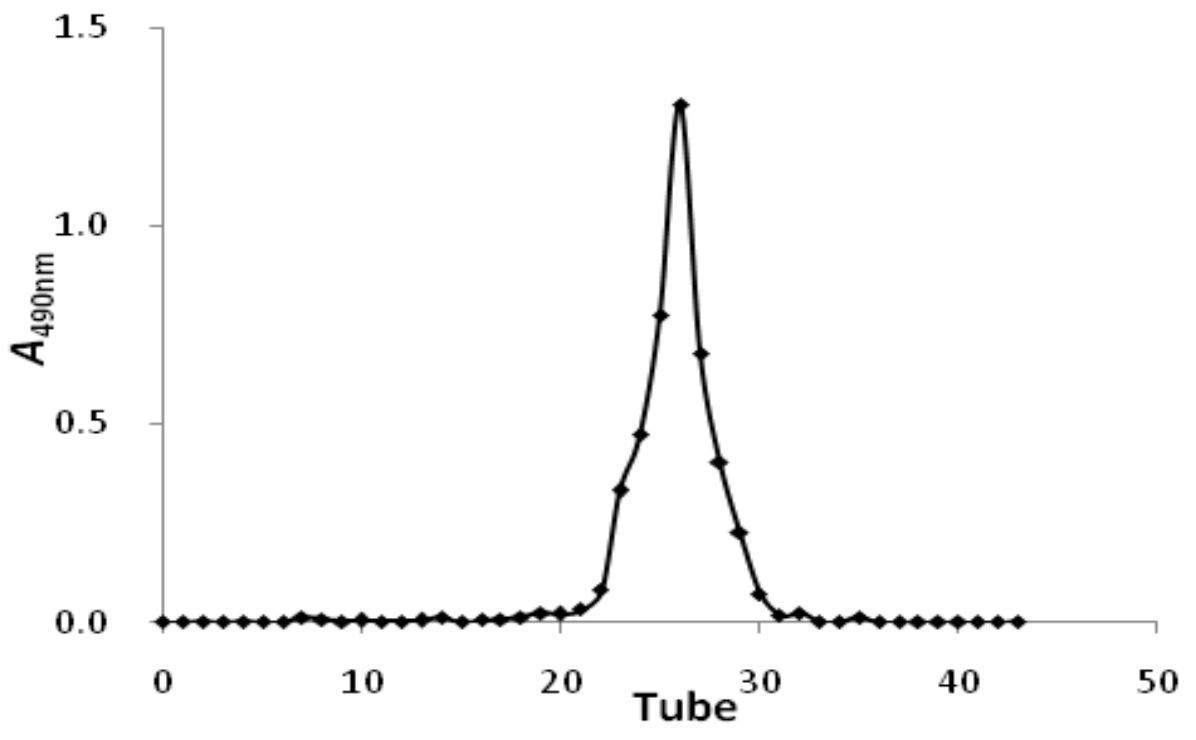

Figure 1: Profile of HSP-1 tested with Sephacryl S-300 HR column chromatography.

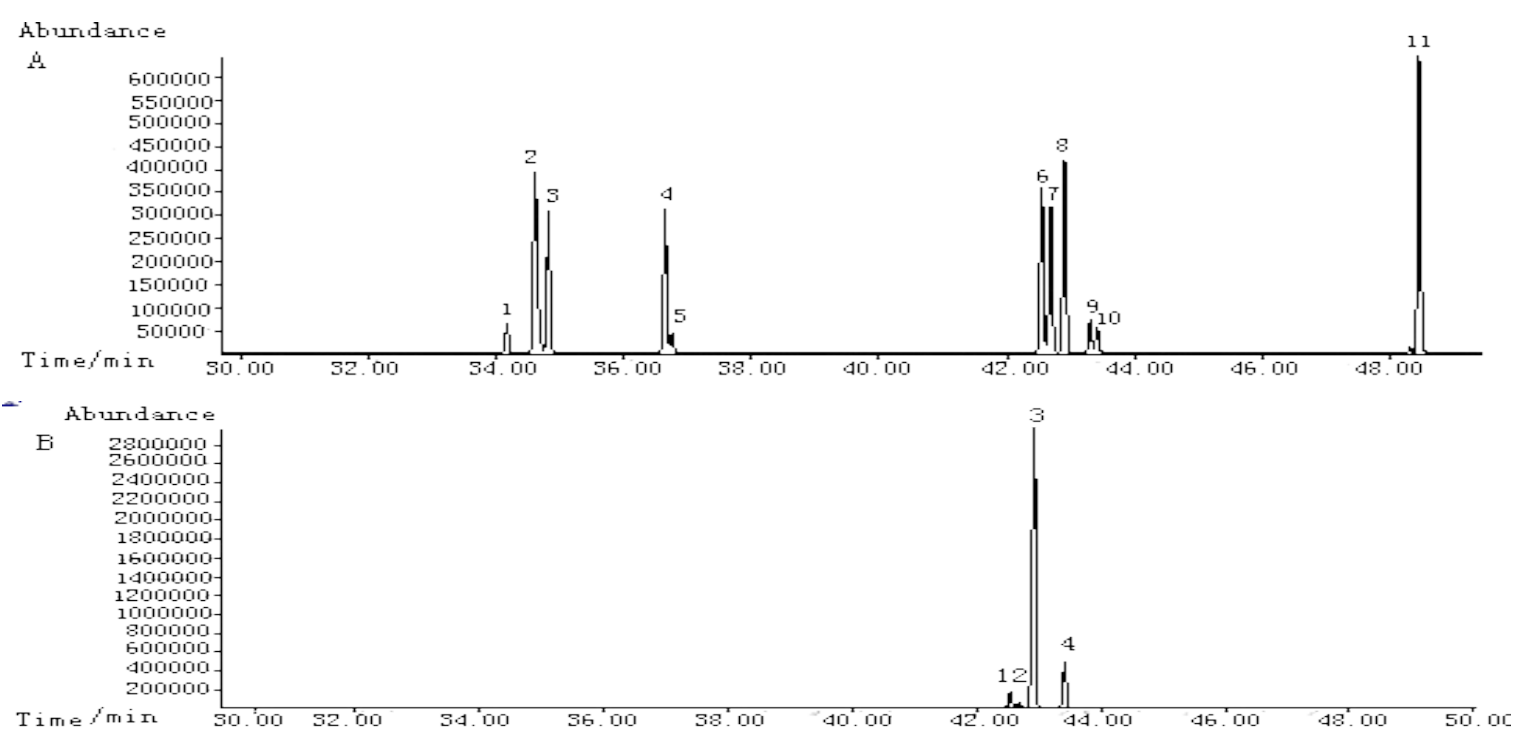

Figure 2: GC-MS profiles of silylation derivatized (A) monosaccharide standards (Peaks: Xyl (1,3); Ara (2); Gal (4, 5, 9, 10); Man (6, 7); Glu (8); Ino (11)) and (B) HSP-1 constituents (Peaks: Man (1, 2); Glu (3); Gal (4)). Three monosaccharides were identified in the hydrolysate of HSP-1, and the composition was D-glucose, D-mannose and D-galactose with a molar ratio of 4.5:1.0:1.4.

the data was assessed by Student's T-test. $P<0.05$ was considered as a statistically significant difference.

\section{Results and Discussion}

\section{Isolation, purification and composition of polysaccharide}

Crude polysaccharide was extracted from the mycelium of Hirsutella sinensis with a yield of $8.239 \%$. After the polysaccharidefractionated by DEAE-cellulose and Sephadex G-100 column with phenol sulfuric acid to detect the polysaccharide distribution, three main fractions were obtained and termed HSP-1, HSP-2 and HSP-3, respectively. The main fraction HSP-1 was chosen for subsequent analysis.
The purification of HSP-1 was tested with the Sephacryl S-300 HR column using phenol sulfuric acid to detect the polysaccharide distribution. A single and symmetric sharp peak was obtained (Figure 1). The UV spectrum of the HSP-1 solution showed no absorption at $260 \mathrm{~nm}$ and $280 \mathrm{~nm}$, indicating that HSP-1 did not contain either nucleic acid or protein; therefore it is a homogeneous polysaccharide. Using different dextran markers passed through a Sephacryl S-300 HR column, the average molecular weight of HSP- 1 was $1.7 \times 10^{4} \mathrm{Da}$. The total carbohydrate content was $92.4 \%$ determined by the phenolsulfuric acid method.

The monosaccharide composition of HSP-1 was measured by silylation derivatization and GC-MS analysis (Figure 2). Three 
Citation: Liu JH, Wang ZJ, Wang Y, Chu J, Zhuang YP, et al. (2014) Structural Elucidation and Antioxidant Activity of a Polysaccharide from Mycelia Fermentation of Hirsutella sinensis Isolated from Ophiocordyceps sinensis. J Bioprocess Biotech 4: 183 doi: 10.4172/21559821.1000183

Page 4 of 6

\begin{tabular}{|c|c|c|}
\hline Methylated sugar & Molar ratio & Linkages \\
\hline $2,3,6-\mathrm{Me}_{3}-\mathrm{Gal}$ & 2.97 & $1,4-$ \\
$2,3,4,6-\mathrm{Me}_{4}-\mathrm{Gal}$ & 1.89 & $\mathrm{~T}-$ \\
$2,3,6-\mathrm{Me}_{3}-\mathrm{Man}$ & 4.12 & $1,4-$ \\
$2,3,6-\mathrm{Me}_{3}-\mathrm{Glu}$ & 17.88 & $1,4-$ \\
3-Me-Glu & 1.00 & $1,2,4,6-$ \\
\hline
\end{tabular}

Table 1: GC-MS results from the methylated product of HSP-1.

\begin{tabular}{|c|c|c|c|}
\hline \multirow{2}{*}{ Fraction } & & Molar ratio & \\
\cline { 2 - 4 } & D-glucose & D-mannose & D-galactose \\
\hline A & 4.835 & 1 & 1.422 \\
B & 5.724 & 1 & 1.463 \\
C & 2.944 & 1 & 6.665 \\
\hline
\end{tabular}

A: precipitation in the dialysis bag

B: supernatant in the dialysis bag

C: fraction out of the dialysis bag

Table 2: GC-MS analysis results of fractions from partial acid hydrolysis of HSP-1.

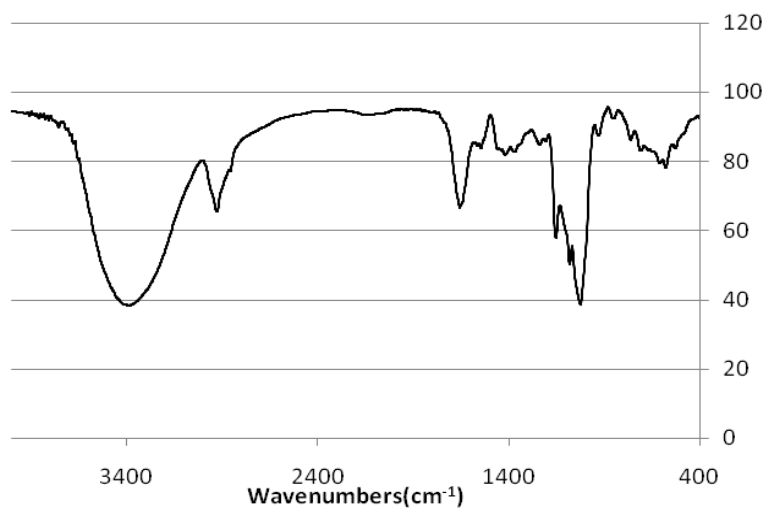

Figure 3: Fourier transform infrared spectrum of HSP-1: OH stretching (3200-3600 $\left.\mathrm{cm}^{-1}\right), \mathrm{CH}$ stretching $\left(2800-3000 \mathrm{~cm}^{-1}\right)$, CO stretching (1600$\left.1700 \mathrm{~cm}^{-1}\right), \mathrm{CH}$ vibration $\left(1200-1400 \mathrm{~cm}^{-1}\right)$ and C-O-C stretching (1000$1200 \mathrm{~cm}^{-1}$ ) implied that the glycosidic structures of HSP-1 were pyranoid form; characteristic absorptions at $840 \mathrm{~cm}^{-1}$ and the absence at $890 \mathrm{~cm}^{-1}$ indicated that there was only $\alpha$-configuration, inexistence of $\beta$-configuration in the structure of HSP-1

monosaccharides were identified in the hydrolysates of HSP-1, and the composition was D-glucose, $\mathrm{D}$-mannose and $\mathrm{D}$-galactose with a molar ratio of 4.5:1.0:1.4.

\section{Structure characterization of HSP-1}

The results of periodate oxidation which showed the ratio of $\mathrm{HIO}_{4}$ consumption to formic acid production was 2.644 (larger than 2). It meant there were 1,2- or 1,2,6- or 1,4- or 1,4,6-linkages in the HSP1 structure which was not able to produce formic acid when being oxidated. Furthermore, Glycerin, erythritol and D-glucose were detected from the periodate oxidation product of HSP-1 by GC-MS. The presence of glycerin suggested that there were 1 - or 1,6- or 1,2 or 1,2,6-linkages in the structure of HSP-1; the presence of erythritol suggested that there should have 1,4- or 1,4,6-linkage; the presence of glucose suggested that a part of glucose in the HSP-1 should be in 1,3or 1,3,6- or 1,2,3- or 1,2,4- or 1,3,4- or 1,2,3,4-linkage which could not be oxidized by periodate.

The methylated HSP-1 was analyzed by GC-MS (Table 1), and the result showed five components, namely 2,3,6-Me $-\mathrm{Gal}, 2,3,4,6-\mathrm{Me}_{4}$ Gal, 2,3,6- $\mathrm{Me}_{3}$-Man, 2,3,6- $\mathrm{Me}_{3}$-Glu, 3-Me-Glu in a molar ratio of 2.97: 1.89: 4.12: 17.88: 1.00 (about 3:2:4:18:1). This pattern of linkage was in good agreement with the results by periodate oxidation and Smith degradation, which showed a good correlation between terminal and the branched residues. Furthermore, the molar ratio was fitted well with the monosaccharide composition and the ratio of HSP-1 measured above.

The monosaccharide compositions of HSP-1 fractions derived from partial acid hydrolysis were subjected to GC-MS analysis (Table 2). The results showed that the precipitation in the dialysis bag (fraction A) which mainly composed of the backbone structure of HSP-1, was mainly consisted of $\mathrm{D}$-glucose with a little amount of $\mathrm{D}$-mannose and $\mathrm{D}$-galactose in a molar ratio of 4.835:1:1.422; the supernatant in the dialysis bag (fraction B) which mainly composed of the branch chains of HSP-1 was consisted of D-glucose, D-mannose and D-galactose in a molar ratio of 5.724:1:1.463; D-glucose, $\mathrm{D}$-mannose and $\mathrm{D}$-galactose in a molar ratio of 2.944:1:6.665 were presented out of the dialysis bag (fraction C), which indicated its existence in the terminal position of the branch chains. The molar ratio from the partial acid hydrolysis matched well with the monosaccharide composition and ratio of HSP-1 and the methylation results measured above.

The Fourier Transform Infrared Spectroscopy (FT-IR) spectrum of HSP-1 was presented in Figure 3. In the spectrum, the attributions of the main absorptions were the characteristic of glycosidic structures and related to $\mathrm{OH}$ stretching $\left(3200-3600 \mathrm{~cm}^{-1}\right)$; $\mathrm{CH}$ stretching (2800$\left.3000 \mathrm{~cm}^{-1}\right)$; CO stretching (1600-1700 $\left.\mathrm{cm}^{-1}\right)$; CH vibration (1200-1400 $\left.\mathrm{cm}^{-1}\right)$; C-O-C stretching $\left(1000-1200 \mathrm{~cm}^{-1}\right)$. It implied that the glycosidic structures of HSP-1 were pyranoidform. Moreover, the characteristic absorptions at $840 \mathrm{~cm}^{-1}$ and the absence at $890 \mathrm{~cm}^{-1}$ indicated that there was only $\alpha$-configuration, inexistence of $\beta$-configuration in the structure of HSP-1.

In the ${ }^{1} \mathrm{H}$ NMR spectrum (Figure 4A), the chemical shifted from 4.9 to $5.6 \mathrm{ppm}$ corresponding to $\alpha$ configuration [22]. The region shifted from 3.3 to $4.2 \mathrm{ppm}$ was assigned to protons of carbons $\mathrm{C} 2$ to C6 of glycosidic ring [23]. In the ${ }^{13} \mathrm{C}$ NMR spectrum (Figure $4 \mathrm{~B}$ ), six strong signals between 60 to $100 \mathrm{ppm}$ were attributed to C1, C2, C3,

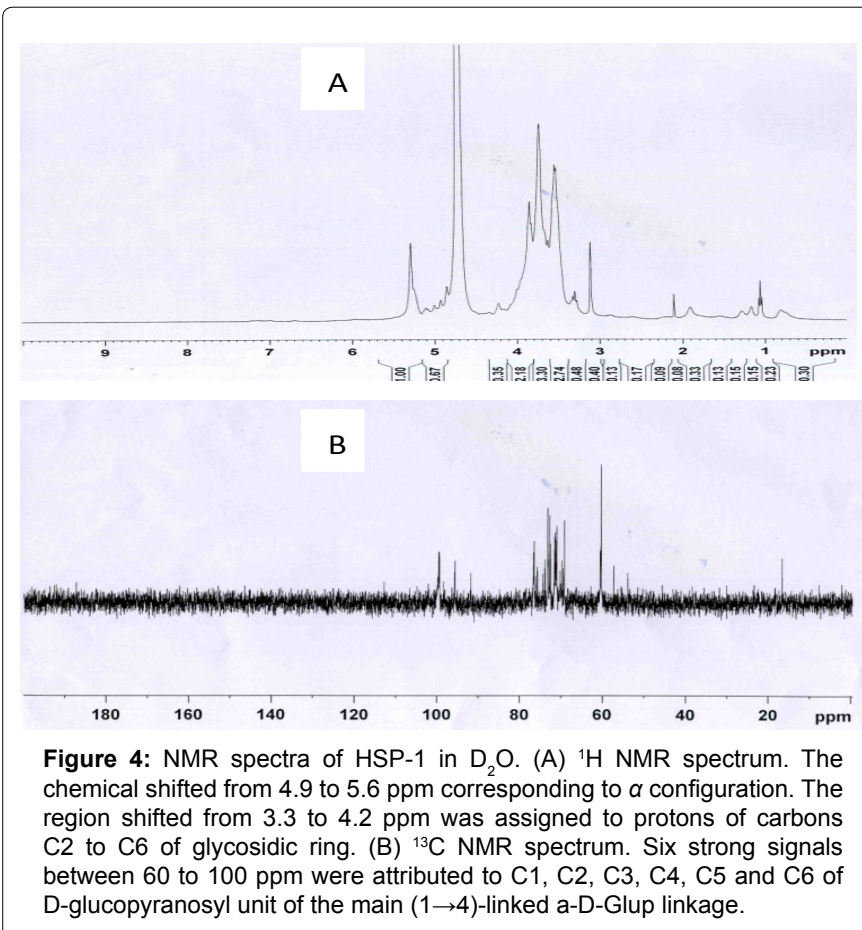


Citation: Liu JH, Wang ZJ, Wang Y, Chu J, Zhuang YP, et al. (2014) Structural Elucidation and Antioxidant Activity of a Polysaccharide from Mycelia Fermentation of Hirsutella sinensis Isolated from Ophiocordyceps sinensis. J Bioprocess Biotech 4: 183 doi: 10.4172/21559821.1000183

Page 5 of 6

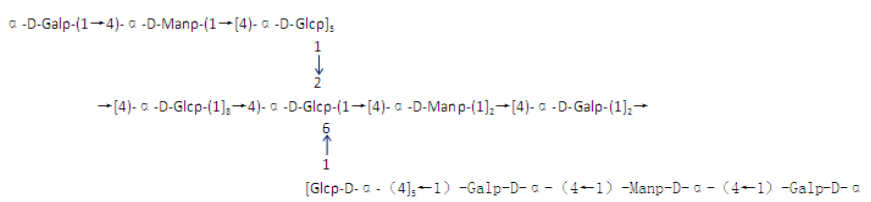

Figure 5: Predicted structure (repeating unit) of HSP-1.

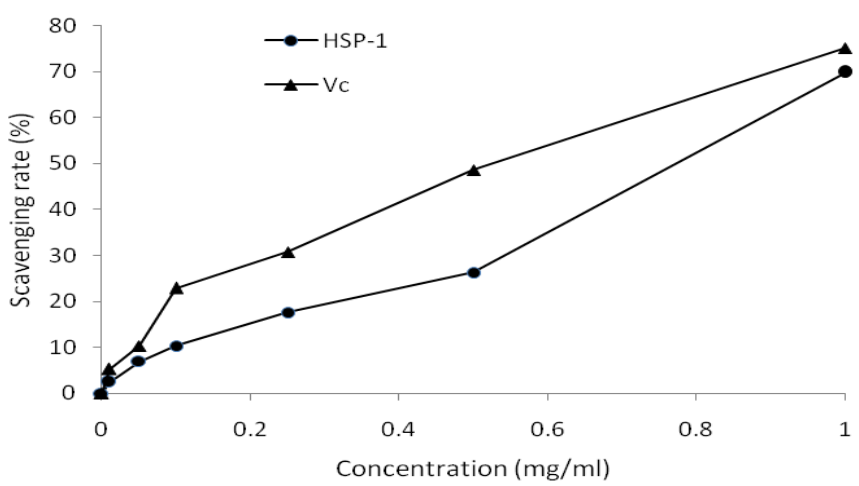

Figure 6: Hydroxyl radical-scavenging activity and Vc. Values (as an antioxidation comparison) of HSP-1.

C4, C5 and C6 of D-glucopyranosyl unit of the main $(1 \rightarrow 4)$-linked a-D-Glup linkage [22]. In the anomeric carbon region of 95-105 ppm, five main signals were detected, namely $\delta 95.70,95.83,99.44,99.53$, and 99.66. Based on the data obtained in the literatures [6,24-26], in the anomeric carbon region, signal at $\delta 95.70$ was attributed to C-1 of $(1 \rightarrow 4)$ - linked $\alpha$-Gal $p, \delta 95.83$ to C-1 of $(1 \rightarrow 4)$-linked $\alpha$-Man $p, \delta 99.44$ to C- 1 of $(1 \rightarrow 2,4,6)$-linked $\alpha$-Glup, $\delta 99.53$ to C-1 of T-linked $\alpha$-Galp and $\delta 99.66$ to $\mathrm{C}-1$ of $(1 \rightarrow 4)$-linked $\alpha$-Glup, respectively. The presence of $\mathrm{C}-1$ signal demonstrated that all monosaccharides should be in pyran ring, because of the resonance of furan ring should be in 107-109 ppm [27]. The results of NMR analysis were in agreement with the results of GC-MS and FT-IR data.

On the basis of the results gained above, the structure of the polysaccharide HSP-1 was demonstrated that HSP-1 was a branched polysaccharide possessing a backbone of $(1 \rightarrow 4)-\alpha$-D-glucose residues ( $70 \%),(1 \rightarrow 4)-\alpha$-D-mannose residues $(\sim 15 \%)$ and $(1 \rightarrow 4)-\alpha$-D-galactose residues $(\sim 15 \%)$. The branches are at the $(1,2,4,6 \rightarrow)-\alpha$-D-glucose residues $(\sim 8 \%)$ of the backbone, mainly composed of $(1 \rightarrow 4)-\alpha$-Dglucose residues, $(1 \rightarrow 4)-\alpha$-D-galactose residues, $(1 \rightarrow 4)-\alpha$-D-mannose residues, and mainly terminated with $\alpha$-D-galactose residues. One of the possible repeating units of HSP-1 was shown in Figure 5.

\section{Hydroxyl radical-scavenging activity of HSP-1}

As shown in Figure 6, HSP-1 was found to have a high hydroxyl radical-scavenging activity in a concentration-dependent manner. In a concentration range from 0 to $1 \mathrm{mg} / \mathrm{mL}$, the scavenging rate was strengthened with the concentration increasing, with an $I C_{50}$ value of $0.834 \mathrm{mg} / \mathrm{mL}$. On the same conditions, Vitamin $\mathrm{C}(\mathrm{Vc})$ showed a slightly higher scavenging rate on the hydroxyl radical, with an $I C_{50}$ value of $0.590 \mathrm{mg} / \mathrm{mL}$. Three repetitions were conducted and the RSD values were not more than $3.0 \%$.

The Reactive Oxygen Species (ROS) like hydroxyl radicals, superoxide anion and hydrogen peroxide, are bound up with the pathogenesis of various diseases [11,28]. Hydroxyl radical can cause severe damage to the biomolecules, so the antioxidant activity of the HSP-1 polysaccharide to hydroxyl radical-scavenging rate in vitro was measured in the present study.

The hydroxyl radical-scavenging activity of the polysaccharides might be influenced by the protein content, Molecular Weight (MW) or monosaccharide composition [29-31]. However, the relationship between the structure and antioxidant activity was still uncertain, therefore the further study was focused on the scavenging activity mechanism of the hydroxyl radicals, which was beneficial to understand the bioactivity of the polysaccharide HSP-1.

Hirsutella sinensis is a kind of hyphomycete; there were few reports about the structure and antioxidant activity of its polysaccharides. One exopolysaccharide produced by Hirsutella $s p$. showed antibacterial activity against gram-positive bacterium and the monosaccharide component of EPS was mannose, galactose and glucose with a molar ratio of 4.0:8.2:1.0. Its molecular weight was $23 \mathrm{kDa}$ [32]. A novel polysaccharide designated EPS-1A with an average molecular weight around $40 \mathrm{kDa}$ was fractionated and purified from the crude exopolysaccharide (EPS) isolated from fermentation broth of Cs-HK1, a Tolypocladium s. Fungus isolated from wild Cordyceps sinensis. EPS1A was composed of glucose, mannose and galactose at 15.2:3.6:1.0 M ratio [11]. Recently, studies could also be found in the research of the polysaccharides isolated from cultured Cordyceps mycelia and Cordyceps militaris. By using anti-oxidation activity-guided fractionation, a 210 $\mathrm{kDa}$ polysaccharide was isolated from cultured Cordyceps mycelia. The polysaccharide, containing glucose, mannose and galactose in a ratio of 1:0.6:0.75, had a strong anti-oxidation activity. The pretreatment of isolated polysaccharide on the cultured rat pheochromocytoma $\mathrm{PCl}_{2}$ cells showed strong protective effect against hydrogen peroxide $\left(\mathrm{H}_{2} \mathrm{O}_{2}\right)_{-}$ induced insult [3]. The water-soluble crude polysaccharides were obtained and purified from the fruiting bodies of cultured Cordyceps militaris, giving main three polysaccharide fractions termed $\mathrm{P}_{50}-1$, $\mathrm{P}_{70}-1$, and $\mathrm{P}_{70}-2$, structural features of $\mathrm{P}_{70}-1$ were investigated. In the in vitro antioxidant assay, $\mathrm{P}_{70}-1$ was found to possess hydroxyl radicalscavenging activity with an $I C_{50}$ value of $0.548 \mathrm{mg} / \mathrm{mL}$ [33]. A novel polysaccharide named CBP-1 was isolated from the fruiting body of cultured Cordyceps militaris; its structural features were investigated. In the in vitro antioxidant assay, CBP-1 was found to possess the hydroxyl radical-scavenging activity with an $I C_{50}$ value of $0.638 \mathrm{mg} / \mathrm{mL}$ [34].

\section{Conclusion}

Previous researches on Hirsutella sinensis showed that fungi polysaccharides have series of pharmacological action and the structure of polysaccharide is closely related with its functions. However, hardly any research focus on the polysaccharide purification from $H$. sinensis, it would be of interest for an in-depth research on the molecular structure and bioactivity of the polysaccharide isolated from Hirsutella sinensis.

In this research, three polysaccharide fractions named HSP1, HSP-2, and HSP-3 were purified from mycelia fermentation of Hirsutella sinensis. The polysaccharide HSP-1 isolated was identified as a heteropolysaccharide, which was composed of glucose, mannose and galactose in a molar ratio of 4.5:1.0:1.4. The HSP-1 was a branched polysaccharide possessing a backbone of $(1 \rightarrow 4)$ - $\alpha$-D-glucose residues $(\sim 70 \%), \quad(1 \rightarrow 4)-\alpha$-D-mannose residues $(\sim 15 \%)$ and $(1 \rightarrow 4)-\alpha-\mathrm{D}$ galactose residues $(\sim 15 \%)$. Anti-oxidation tests showed that HSP-1 could sweep the hydroxyl radical with an $I C_{50}$ value of $0.834 \mathrm{mg} / \mathrm{mL}$.

\section{Acknowledgement}

This work was financially supported by Grant from the Major State Basic Research Development Program of China (973 Program), No. 2013CB733600, and 
Citation: Liu JH, Wang ZJ, Wang Y, Chu J, Zhuang YP, et al. (2014) Structural Elucidation and Antioxidant Activity of a Polysaccharide from Mycelia Fermentation of Hirsutella sinensis Isolated from Ophiocordyceps sinensis. J Bioprocess Biotech 4: 183 doi: 10.4172/21559821.1000183

Page 6 of 6

2012CB72100x, and Science and technology support plan of Hebei (13272803D) We also thank Zhu Feng Cordyceps Pharmacy Corporation, LTD. P R (Qinghai, China) for donating the industrial strain.

\section{References}

1. Carbonero ER, Smiderle FR, Gracher AHP, Mellinger CG, Torri G, et al. (2006) Structure of two glucans and a galactofuranomannan from the lichen Umbilicaria mammulata. Carbohydr Polym 63: 13-18.

2. Novak M, Vetvicka V (2008) Beta-glucans, history, and the present immunomodulatory aspects and mechanisms of action. J Immunotoxicol 5: 4757.

3. Yu R, Yang W, Song L, Yan C, Zhang Z, et al. (2007) Structural characterization and antioxidant activity of a polysaccharide from the fruiting bodies of cultured Cordyceps militaris. Carbohydr Polym 70: 430-436.

4. Ye M, Qiu T, Peng W, Chen WX, Ye YW, et al. (2011) Purification, characterization and hypoglycemic activity of extracellular polysaccharides from Lachnum calyculiforme. Carbohydr Polym 86: 285-290.

5. Lee JS, Kwon JS, Yun JS, Pahk JW, Shin WC, et al. (2010) Structura characterization of immunostimulating polysaccharide from cultured mycelia of Cordyceps militaris. Carbohydr Polym 80: 1011-1017.

6. Chi AP, Chen JP, Wang ZZ, Xiong ZY, Li QX (2008) Morphological and structural characterization of a polysaccharide from Gynostemma pentaphyllum Makino and its anti-exercise fatigue activity. Carbohydr Polym 74: 868-874.

7. Yan JK, Wang WQ, Li L, Wu JY (2011) Physiochemical properties and antitumor activities of two a-glucans isolated from hot water and alkaline extracts of Cordyceps (Cs-HK1) fungal mycelia. Carbohydr Polym 85: 753-758.

8. Zhu JS, Halpern GM, Jones K (1998) The scientific rediscovery of an ancient Chinese herbal medicine: Cordyceps sinensis: part I. J Altern Complement Med 4: 289-303.

9. Yalin W, Cuirong S, Yuanjiang P (2006) Studies on isolation and structura features of a polysaccharide from the mycelium of a Chinese edible fungus (Cordyceps sinensis). Carbohydr Polym 63: 251-256.

10. Wu Y, Hu N, Pan Y, Zhou L, Zhou X (2007) Isolation and characterization of a mannoglucan from edible Cordyceps sinensis mycelium. Carbohydr Res 342 $870-875$

11. Yan JK, Li L, Wang ZM, Wu JY (2010) Structural elucidation of an exopolysaccharide from mycelial fermentation of a Tolypocladium sp. fungus isolated from wild Cordyceps sinensis. Carbohydr Polym 79: 125-130.

12. Chen YQ, Wang N, Qu L, Li T, Zhang W (2001) Determination of the anamorph of Cordyceps sinensis inferred from the analysis of the ribosomal DNA internal transcribed spacers and 5.8S rDNA. Biochem Syst Ecol 29: 597-607.

13. Liu ZY, Yao YJ, Liang ZQ, Liu AY, Pegler DN, et al. (2001) Molecular evidence for the anamorph-teleomorph connection in Cordyceps sinensis. Mycol Res 105: 827-832.

14. Staub AM (1965) Removal of protein-Sevag method. Method Carbohydr Chem 5: 5-6.

15. Dubois M, Gilles K, Hamilton JK, Rebers PA, Smith F (1956) Colorimetric method for determination of sugars and related substances. Anal Chem 28 350-356.

16. Wang GY, Liang ZY, Zhang LP (2001) Studies on the structure of JS,-The water soluble polysaccharide isolated by alkaline from Hippophae rhamnoides L. Chem J Chin Univ 22: 1688-1690.

17. Linker A, Evans LR, Impallomeni G (2001) The structure of a polysaccharide from infectious strains of Burkholderia cepacia. Carbohydr Res 335: 45-54.
18. Aspinall GO, Ferrier RJ (1957) A spectrophotometric method for the determination of periodate consumed during the oxidation of carbohydrates. Chem Ind 7: 1216-1221.

19. Needs PW, Selvendran R (1993) Avoiding oxidative degradation during sodium hydroxide/methyl iodide-mediated carbohydrate methylation in dimethyl sulfoxide. Carbohydr Res 245: 1-10

20. Bjorndal H, Lindberg B, Svenndon S (1967) Mass spectrometry of partially methylated alditol acetates. Carbohydr Res 5: 433-440.

21. He ZS, Luo H, Cao CH, Cui ZW (2004) Photometric determination of hydroxyl free radical in Fenton system by brilliant green. Amer J Chin Clin Med 6: 236237

22. Kawagishi H, Kanao T, Mizuno T, Shimura K, Ito H, et al. (1990) Formolysis of a potent antitumor $(1 \rightarrow 6)-\beta$-d-glucan-protein complex from Agaricus blaze fruiting bodies and antitumor activity of the resulting products. Carbohydr Polym 12: 393-403.

23. Chauveau C, Talaga P, Wieruszeski JM, Strecker G, Chavant L (1996) A watersoluble beta-D-glucan from Boletus erythropus. Phytochemistry 43: 413-415.

24. Gulin S, Kussak A, Jansson PE, Widmalm G (2001) Structural studies of S-7, another exocellular polysaccharide containing 2-deoxy-arabino-hexuronic acid Carbohydr Res 331: 285-290.

25. Xu C, Chen YL, Zhang M (2004) Structural characterization of the polysaccharide DMP2a-1 from Dendrobium moniliforme. Chin Pharm J 39: 900-902.

26. Zhang WJ (1999) Technology of biochemical research on compound polysaccharide. Hangzhou: Zhejiang University Press.

27. Wang Y, Yin H, Lv X, Wang Y, Gao H, et al. (2010) Protection of chronic renal failure by a polysaccharide from Cordyceps sinensis. Fitoterapia 81: 397-402.

28. Busciglio J, Yankner BA (1995) Apoptosis and increased generation of reactive oxygen species in Down's syndrome neurons in vitro. Nature 378: 776-779.

29. Chen HX, Zhang M, Qu ZS, Xie BJ (2008) Antioxidant activities of different fractions of polysaccharide conjugates from green tea (Camellia sinensis). Food Chem 106: 559-563.

30. Lin CL, Wang CC, Chang SC, Inbaraj BS, Chen BH (2009) Antioxidative activity of polysaccharide fractions isolated from Lycium barbarum Linnaeus. Int $\mathrm{J}$ Biol Macromol 45: 146-151.

31. Zhu BW, Wang LS, Zhou DY, Li DM, Sun LM, et al. (2008) Antioxidant activity of sulphated polysaccharide conjugates from abalone (Haliotis discus hannai Ino). Eur Food Res Technol 227: 1663-1668.

32. Li R, Jiang XL, Guan HS (2010) Optimization of mycelium biomass and exopolysaccharides production by Hirsutella sp. In submerged fermentation and evaluation of exopolysaccharides antibacterial activity. African Journal of Biotechnology 9: 195-202.

33. Li SP, Zhao KJ, Ji ZN, Song ZH, Dong TT, et al. (2003) A polysaccharide isolated from Cordyceps sinensis, a traditional Chinese medicine, protects PC12 cells against hydrogen peroxide-induced injury. Life Sci 73: 2503-2513.

34. Yu RM, Yin Y, Yang W, Ma WL, Yang L, et al. (2009) Structural elucidation and biological activity of a novel polysaccharide by alkaline extraction from cultured Cordyceps militaris. Carbohydr Polym 75: 166-171. 